\title{
Twenty five year follow-up for breast cancer incidence and mortality of the Canadian National Breast Screening Study: randomised screening trial
}

\author{
(c) (1) (1) OPEN ACCESS
}

\author{
Anthony B Miller professor emeritus ${ }^{1}$, Claus Wall data manager ${ }^{1}$, Cornelia J Baines professor \\ emerita $^{1}$, Ping Sun statistician ${ }^{2}$, Teresa To senior scientist ${ }^{3}$, Steven A Narod professor ${ }^{12}$
}

'Dalla Lana School of Public Health, University of Toronto, Toronto, Ontario M5T 3M7, Canada; ${ }^{2}$ Women's College Research Institute, Women's College Hospital, Toronto, Ontario M5G 1N8, Canada; ${ }^{3}$ Child Health Evaluative Services, The Hospital for Sick Children, Toronto, Ontario, Canada

\begin{abstract}
Objective To compare breast cancer incidence and mortality up to 25 years in women aged 40-59 who did or did not undergo mammography screening.

Design Follow-up of randomised screening trial by centre coordinators, the study's central office, and linkage to cancer registries and vital statistics databases.

Setting 15 screening centres in six Canadian provinces, 1980-85 (Nova Scotia, Quebec, Ontario, Manitoba, Alberta, and British Columbia).

Participants 89835 women, aged 40-59, randomly assigned to mammography (five annual mammography screens) or control (no mammography).

Interventions Women aged 40-49 in the mammography arm and all women aged 50-59 in both arms received annual physical breast examinations. Women aged 40-49 in the control arm received a single examination followed by usual care in the community.

Main outcome measure Deaths from breast cancer.

Results During the five year screening period, 666 invasive breast cancers were diagnosed in the mammography arm ( $n=44925$ participants) and 524 in the controls ( $n=44910)$, and of these, 180 women in the mammography arm and 171 women in the control arm died of breast cancer during the 25 year follow-up period. The overall hazard ratio for death from breast cancer diagnosed during the screening period associated with mammography was 1.05 (95\% confidence interval 0.85 to 1.30 ). The findings for women aged $40-49$ and $50-59$ were almost identical. During the entire study period, 3250 women in the mammography arm and 3133 in the control arm had a diagnosis of breast cancer, and 500 and 505, respectively, died of breast cancer. Thus the cumulative mortality from breast cancer was similar between women in the mammography arm and in the control arm (hazard ratio $0.99,95 \%$ confidence interval 0.88 to 1.12 ). After 15 years of follow-up a residual excess of 106 cancers was observed in the mammography arm, attributable to over-diagnosis.
\end{abstract}

Conclusion Annual mammography in women aged 40-59 does not reduce mortality from breast cancer beyond that of physical examination or usual care when adjuvant therapy for breast cancer is freely available. Overall, 22\% (106/484) of screen detected invasive breast cancers were over-diagnosed, representing one over-diagnosed breast cancer for every 424 women who received mammography screening in the trial.

\section{Introduction}

Regular mammography screening is done to reduce mortality from breast cancer. Mammogram detected non-palpable breast cancers are smaller on average than clinically palpable breast cancers. Small breast cancers confer a better prognosis than large ones. However, survival in the context of a screening programme is not predictive of reduced mortality because of lead time bias, length bias, or over-diagnosis. ${ }^{1}$ Thus the benefit of mammography screening must be evaluated in randomised screening trials, with breast cancer mortality as the endpoint.

Over-diagnosis refers to the possibility that a screen detected cancer might not otherwise become clinically apparent during the lifetime of the woman. ${ }^{23}$ Over-diagnosis can be estimated in a randomised screening trial when a sufficiently long period has elapsed from the cessation of screening - that is, when all cancers should have become clinically apparent in both trial arms.

In 1980 a randomised controlled trial of screening mammography and physical examination of breasts in 89835 women, aged 40 to 59, was initiated in Canada, the Canadian National Breast Screening Study. ${ }^{4-7}$ It was designed to tackle research questions that arose from a review of mammography screening in $\mathrm{Canada}^{8}$ and the report by the working group to review the US Breast Cancer Detection and Demonstration projects. ${ }^{9}$ At that time the only breast screening trial that had reported results was that conducted within the Health Insurance Plan of Greater New York. ${ }^{10}{ }^{11}$ Benefit from combined 
mammography and breast physical examination screening was found in women aged 50-64, but not in women aged 40-49.

Therefore the Canadian National Breast Screening Study was designed to evaluate the benefit of screening women aged 40-49 compared with usual care and the risk benefit of adding mammography to breast physical examination in women aged 50-59. It was not deemed ethical to include a no screening arm for women aged 50-59.

We have now followed the study participants for a mean of 22 years. Previously the trial was reported in two components, women aged $40-49^{4}$ and women aged $50-59^{57}$ on enrolment. As the results from the mammography and control arms were similar in both age groups, we have combined the age groups and compare breast cancer incidence and mortality rates up to 25 years between the two arms of the trial.

\section{Methods}

Participants were recruited to the study by a general publicity campaign, by reviewing population lists and sending personal invitation letters, by group mailings, and through family doctors. ${ }^{4}$ Women were eligible if they were aged 40-59, had had no mammography in the previous 12 months, had no history of breast cancer, and were not pregnant. Recruitment was planned to enrol 50000 women aged 40-49 and 40000 aged 50-59 years. Before randomisation, the women who volunteered to participate signed an informed consent form approved by the University of Toronto's Human Experimentation Committee. The study was conducted in 15 screening centres in six Canadian provinces (Nova Scotia, Quebec, Ontario, Manitoba, Alberta, and British Columbia). All screening centres were located in teaching hospitals or in cancer centres. The central coordinating centre was at the University of Toronto.

Participants then had a physical (clinical) breast examination and were taught breast self examination by trained nurses, or in the province of Quebec, by doctors (fig $1 \Downarrow$ ). The examiners had no role in the randomisation that followed; this was performed by the study coordinators in each centre.

Randomisation was individual and stratified by centre and five year age group. ${ }^{5}$ Irrespective of the findings on physical examination, women aged 40-49 were independently and blindly assigned randomly to receive mammography or no mammography. Those allocated to mammography were offered another four rounds of annual mammography and physical examination, those allocated to no mammography were told to remain under the care of their family doctor, thus receiving usual care in the community, although they were asked to complete four annual follow-up questionnaires. Women aged 50-59 were randomised to receive mammography or no mammography, and subsequently to receive four rounds of annual mammography and physical examination or annual physical breast examinations without mammography at their screening centre.

For those women enrolled in the final year of recruitment, a total of four annual screens were offered. The screening period was defined as the first five years from randomisation for each woman and the follow-up period as years 6 to 25 . As previously reported, ${ }^{45}$ in the mammography arm full compliance with screening after screen 1 (when compliance was $100 \%$ ) varied from $86 \%$ (for screen 5) to $90 \%$ (for screen 2). In addition a small proportion (up to $3 \%$ ) of the women attended and accepted breast examination but refused mammography. Of the women who failed to attend 3\% to $7 \%$ submitted questionnaires. Over 93\% of participants in the control arm aged 40-49 returned their annual questionnaire, whereas compliance with annual breast examination screening for those in the control arm aged 50-59 varied between $89 \%$ (for screen 2) and $85 \%$ (for screen 5); only questionnaires were obtained for $3 \%$ to $7 \%$ of the women.

Women with abnormal findings either on physical examination or on mammography were referred to a special review clinic directed by the surgeon affiliated with the study centre. If indicated, diagnostic mammography was performed. If further diagnostic investigation such as a biopsy was required, the woman was referred to a specialist chosen by her family doctor. Women for whom these investigations did not result in a diagnosis of breast cancer resumed their normal participation in the trial; women with a diagnosis of breast cancer were treated by specialists selected by the woman's family doctor and were followed by us through annual communication with the selected surgeon until 30 June 1996.

During the screening period, centre coordinators collected surgical and pathology reports for all diagnostic and therapeutic procedures, including those for women aged 40-49 who were not returning for further screening, and for interval cancers. A pathologist affiliated with the Canadian National Breast

Screening Study obtained and reviewed representative slides of all biopsy samples. Cancer treatment was arranged through the participant's doctor and was not influenced by the study team. Canada has a universal healthcare system. No financial barrier exists to accessing appropriate diagnostic investigation or treatment.

Throughout the study two view film screen mammography was used. In accordance with standard practice in North America, craniocaudal and mediolateral views were used until 1985.

Thereafter craniocaudal and mediolateral oblique views were used. ${ }^{6}$ Facilities and equipment for modern film screen mammography were prerequisites. ${ }^{6}$ Quality control procedures were established for radiation physics and mammography interpretation. ${ }^{7}$ Breast examiners received a month of training by the centre surgeon before conducting examinations in the study. ${ }^{5}$

In the remainder of this report we refer to the mammography plus breast physical examination arm in both age groups as the mammography arm, and the no mammography arms (usual care for women aged 40-49 and annual breast physical examinations for women aged 50-59) as the control arm.

\section{Follow-up}

The screening centres closed in 1988. Thereafter the Canadian National Breast Screening Study coordinating centre continued to follow the women with a diagnosis of breast cancer in the screening period through their treating surgeon until 30 June $1996{ }^{67}$ To determine the underlying cause of death for those women with breast cancer who died, expert oncologists blind as to allocation obtained and reviewed detailed documentation on the terminal illness. ${ }^{67}$ Subsequent to 30 June 1996, passive follow-up of all participants was carried out through record linkage. The cut-off date for passive follow-up was 31 December 2005. Using linkage to the Canadian Cancer Registry and the Canadian national mortality database, maintained by Statistics Canada in Ottawa, we ascertained all dates of breast cancer diagnoses and all dates of death from breast cancer that occurred before the cut-off date. The study investigators received reports on all deaths, with the certified underlying cause of death as coded within Statistics Canada. The denominators for the breast cancer incidence and mortality rates reported were all women randomised to the two arms of the trial. 


\section{Statistical analysis}

Tumour characteristics - We collected data on tumour size, lymph node status, and tumour palpability (yes or no) for women with a diagnosis of breast cancer in the screening period. For this analysis, we considered only invasive cancers as events. We also obtained similar data for $63 \%$ of the cancers diagnosed in years 6-11 of the follow-up period. Cancers in the mammography and control arms (including interval cancers) were compared for these three characteristics and the $\chi^{2}$ test used to compare differences.

Survival rates-We evaluated the 10 year and 25 year survival rates for all women with a diagnosis of breast cancer in the screening period (years 1-5) and for all cases diagnosed during the entire study period (years 1 to 25). We also conducted analyses assuming the screening period to be six years and seven years. Survival was estimated from time of diagnosis to time of death from breast cancer, death from another cause, or date last known to be alive. Women not known to be dead were assumed to be alive on 31 December 2005. We carried out subanalyses, stratifying the participants by tumour size $(\mathrm{cm})$, nodal status, palpability of tumour, and mammography and control arms.

Mortality rates-Participants were followed for death from breast cancer from the date of randomisation until 31 December 2005. Women who died from another cause were censored at the date of death. The primary analysis included only deaths from invasive breast cancers diagnosed during the screening period. We carried out subanalyses on deaths from prevalent cancers (cancers detected at the first screening round) and deaths from incident cancers (cancers detected at screening rounds 2 to 5) plus cancers detected between screening rounds and cancers detected within one year of the last screen (interval cancers). We used Cox proportional hazards model to calculate hazard ratios with $95 \%$ confidence intervals. A $P$ value of 0.05 was used as the cut-off for statistical significance. All analyses were conducted using SAS.

\section{Results}

\section{Breast cancer occurrence}

The 89835 women were followed for incident breast cancers for up to 25 years from the date of randomisation (mean 21.9 years). A total of 1190 breast cancers were diagnosed during the screening period (666 in the mammography arm and 524 in the control arm), and a further 5193 were ascertained in the follow-up period (2584 in the mammography arm and 2609 in the control arm) (table $1 \Downarrow$ ). Of the 666 cancers detected in the mammography arm during the screening period, 484 were screen detected $(73.3 \%), 176$ were interval cancers $(26.7 \%)$, and data were missing for six.

During the screening period the mean size of the cancers diagnosed in the mammography arm was $1.91 \mathrm{~cm}$ and in the control arm was $2.10 \mathrm{~cm}(\mathrm{P}=0.01)$ (table $2 \Downarrow)$. In the mammography arm, $30.6 \%$ of cancers $(n=204)$ were node positive and $68.2 \%(\mathrm{n}=454)$ were palpable. In the control arm, $32.4 \%$ of the cancers $(\mathrm{n}=170)$ were node positive $(\mathrm{P}=0.53$ for difference) and all were palpable. Overall, 454 palpable cancers were detected in the mammography arm and 524 in the control arm, whereas similar proportions of palpable cancers were identified as node positive. On average, palpable cancers were larger than cancers that were detected only by mammography $(2.1 \mathrm{~cm} v 1.4 \mathrm{~cm} ; \mathrm{P}<0.001)$ and were more likely to be node positive $(34.7 \% v 16.5 \% ; \mathrm{P}<0.001)$ (table 2$)$.

\section{Breast cancer survival}

Overall, 1005 women died from breast cancer during the 25 year follow-up period $(1.1 \%)$ including 351 of 1190 women $(29.4 \%)$ with a diagnosis during the screening period. The 25 year survival was $77.1 \%$ for women with tumours of less than $2 \mathrm{~cm}$, compared with $54.7 \%$ for tumours greater than $2 \mathrm{~cm}$ (hazard ratio $0.46,95 \%$ confidence interval 0.37 to 0.58 ; $\mathrm{P}<0.001)$. The 25 year survival was $70.6 \%$ for women with breast cancer detected in the mammography arm and $62.8 \%$ for women with cancers diagnosed in the control arm $(0.79,0.64$ to $0.97 ; \mathrm{P}=0.02$ ). The 25 year survival for women with a palpable cancer was similar between women in the mammography arm and control arm (66.3\% and 62.8\%). The 25 year survival of women with breast cancer diagnosed by mammography only (non-palpable) was $79.6 \%$. In the mammography arm, the survival of women with a non-palpable cancer was much longer than that of women with a palpable cancer $\left(0.58,0.41\right.$ to $\left.0.82 ; \mathrm{P}<10^{-4}\right)$ as was the survival of women with a screen detected cancer compared with interval cancer (0.61, 0.45 to $0.82 ; \mathrm{P}=0.001)$.

\section{Breast cancer mortality}

All cause mortality was 9477 (10.6\%) in the follow-up period. The 25 year cumulative mortality from all causes of death was similar between women in the mammography and control arms (fig $2 \Downarrow)(1.02,0.98$ to $1.06 ; \mathrm{P}=0.28)$. Overall, 1005 deaths occurred from breast cancer. The 25 year cumulative mortality from breast cancer was similar between women in the mammography arm and control arm (fig 2$)(0.99,0.88$ to 1.12 ; $\mathrm{P}=0.87$ ).

During the screening period, 361 deaths occurred from breast cancer (table $3 \Downarrow$ ). Overall, the 25 year cumulative mortality from breast cancers diagnosed during the screening period was similar between women in the mammography and control arms (fig $3 \Downarrow)(1.05,0.85$ to $1.30 ; \mathrm{P}=0.63)$. The hazard ratio remained similar if the screening period was extended to six years $(1.06$, 0.87 to $1.29 ; \mathrm{P}=0.55)$ or seven years $(1.07,0.89$ to $1.29 ; \mathrm{P}=0.46)$. For women aged 40-49 at assignment the hazard ratio for 25 year breast cancer specific mortality associated with mammography was 1.09 (95\% confidence interval 0.80 to 1.49 ; $\mathrm{P}=0.58)$ and for women aged 50-59 at assignment was 1.02 ( 0.77 to $1.36 ; \mathrm{P}=0.88)$. The hazard ratio for 25 year breast cancer specific mortality associated with mammography from prevalent cancers only (diagnosed in first screening round) was 1.47 (1.01 to $2.13 ; \mathrm{P}=0.04)$, and the hazard ratio for deaths from incident cancers (those diagnosed in years 2 to 5$)$ was 0.90 (0.69 to 1.16 ; $\mathrm{P}=0.40$ ).

\section{Over-diagnosis}

At the end of the screening period, an excess of 142 breast cancer cases occurred in the mammography arm compared with control arm $(666 v 524)$ (fig $4 \Downarrow)$. Fifteen years after enrolment, the excess became constant at 106 cancers. This excess represents $22 \%$ of all screen detected invasive cancers-that is, one over-diagnosed breast cancer for every 424 women who received mammography screening in the trial.

\section{Discussion}

In this analysis of findings from the Canadian National Breast Screening Study, we have extended the previously reported follow-up at 11-16 years ${ }^{67}$ to 25 years, and for the first time report an estimate of the amount of over-diagnosis resulting from mammography screening. We still found no reduction in 
breast cancer mortality from mammography screening in a programme offering five annual screens, neither in women aged 40-49 at study entry nor in women aged 50-59. Although the difference in survival after a diagnosis of breast cancer was significant between those cancers diagnosed by mammography alone and those diagnosed by physical examination screening, this is due to lead time, length time bias, and over-diagnosis. At the end of the screening period, an excess of 142 breast cancers occurred in the mammography arm compared with the control arm, and at 15 years the excess remained at 106 cancers. This implies that $22 \%(106 / 484)$ of the screen detected invasive cancers in the mammography arm were over-diagnosed. This represents one over-diagnosed breast cancer for every 424 women who received mammography screening in the trial. Assuming that nearly all over-diagnosed cancers in the Canadian National Breast Screening Study were non-palpable, 50\% (106/212) of mammogram detected, non-palpable cancers were over-diagnosed.

\section{Strengths and limitations of this study}

We believe that the lack of an impact of mammography screening on mortality from breast cancer in this study cannot be explained by design issues, lack of statistical power, or poor quality mammography. It has been suggested that women with a positive physical examination before randomisation were preferentially assigned to the mammography arm. ${ }^{12}{ }^{13}$ If this were so, the bias would only impact on the results from breast cancers diagnosed during the first round of screening (women retained their group assignment throughout the study). However, after excluding the prevalent breast cancers from the mortality analysis, the data do not support a benefit for mammography screening (hazard ratio $0.90,95 \%$ confidence interval 0.69 to 1.16). It has also been suggested that women in the screening group might have been at higher a priori risk of developing breast cancer than women in the control group. ${ }^{13}$ After the screening period ended, however, breast cancer was diagnosed in $5.8 \%$ of women in the mammography arm and in $5.9 \%$ of women in the control arm $(\mathrm{P}=0.80)$, showing that the risk of breast cancer was identical between the compared groups. It has also been suggested that the lack of benefit from mammography screening found in the study could have been due to mammography screening ongoing in the community. We tackled this issue for women aged 40-49 in an earlier report ${ }^{7}$ and found that after adjusting for use of mammography in the community in the control group, largely for diagnosis, there was still no indication of benefit from the mammography screening in the intervention group. Mammography screening programmes fall under provincial jurisdiction and were not introduced in Canada until after screening ceased in the Canadian National Breast Screening Study, initially in British Columbia in 1988, then in Ontario and Alberta in 1990, Nova Scotia in 1991, Manitoba in 1995, and Quebec in $1998 .{ }^{14} \mathrm{We}$ do not have data on the participation of the participants in these programmes, but we have no reason to suspect it was differential between the two arms of the Canadian National Breast Screening Study. These programmes did not necessarily include breast examination and most excluded women in their 40s. In our analyses we included deaths of any woman with breast cancer detected by these programmes.

Long term follow-up was conducted passively on participants, by record linkage to national databases. This allowed us to capture incident cancers and deaths for women who moved within the country, and for Canadian women who died in the United States, as death certificates on such women are forwarded to Statistics Canada. An occupational cohort study estimated that record linkage to the Canadian national death index was at least $95 \%$ complete. $^{15}$

We have shown that the sensitivity of the mammography employed in the screening centres was representative of the quality of the technology delivered at cancer centres and teaching hospitals and that the screening examination was properly conducted. ${ }^{16-18}$ Of the 666 breast cancers diagnosed in the mammography arm during the screening period, 212 (32\%) were detected by mammography only, and on average these were $0.7 \mathrm{~cm}$ smaller than those detected by physical examination $(1.4 \mathrm{~cm} v 2.1 \mathrm{~cm})$. Cancers detected in the mammography arm were significantly smaller than cancers detected in the control arm $(1.9 \mathrm{~cm} v 2.1)$, and the 25 year survival of women with breast cancer diagnosed in the mammography arm was superior to that of the women with a diagnosis in the control arm (70.6\% $v 62.8 \%$ ). Furthermore, during the screening period 70 fewer palpable cancers were detected in the mammography arm than in the control arm (454v 524). Some of this difference may be due to random fluctuation, but this may also be the consequence of shifting 70 women from having a palpable to a non-palpable cancer at presentation through earlier detection, commensurate with the reduction in mean tumour size.

Our study is strengthened by the long follow-up period and the acquisition of information on incident cancers that occurred beyond the screening period. The interpretation of our results is aided by additional data we acquired on tumour size, nodal status, mammographic detection, and palpability of tumours. In particular, during the screening period we detected 524 cancers (all palpable, mean size $2.10 \mathrm{~cm}$ ) in the control arm and 666 cancers (mean size $1.98 \mathrm{~cm}$ ) in the mammography arm. Within the screening arm, $454(68 \%)$ of the detected palpable cancers were (mean size $2.10 \mathrm{~cm}$ ) identified at the time of the mammography through physical examination. Screening was annual, and therefore it is to be expected that in programmes with less frequent screening (for example, every two or three years) the proportion of invasive cancers detected in the mammography arm that would be palpable would be even higher. From this we infer that if there is benefit from a mammography only screening programme, it is derived through cancers detectable by a thorough breast physical examination.

\section{Comparison with other studies}

Our long term result differs from the finding of the 29 year follow-up of the Swedish Two-County Trial, which reported a $31 \%$ reduction in mortality associated with screening. ${ }^{19}$ The analysis of the Swedish trial was based on invitation to screen (rather than actual screening), informed consent was not implemented, randomisation was at the county level (not individually), and screening was done every 24 to 33 months (not annually). The persisting divergence of breast cancer mortality with time suggests an initial imbalance of the compared groups, not a benefit of screening mammography. Of note, $68 \%$ of the cancers in the screening arm in the Swedish trial were detected through screening, compared with $74 \%$ in our study, and adjuvant therapy was not given, ${ }^{20}$ whereas it was in the Canadian National Breast Screening Study. ${ }^{1}$ Tumours in the control group of the Swedish Two-County study were on average $2.8 \mathrm{~cm}$, larger than in our study. ${ }^{21}$ The mean size of the tumours in our control group was relatively small $(2.1 \mathrm{~cm})$, and $66 \%$ were node negative. The difference in mortality associated with tumours less than $2 \mathrm{~cm}$ compared with larger tumours is substantial.

Our estimate of over-diagnosis is smaller than that of a review of data from the Surveillance, Epidemiology, and End Results 
programme from 1976 to 2008, which estimated that over-diagnosis accounted for $31 \%$ of all breast cancers. ${ }^{22}$ However, the reviewers considered a wider age range than in the Canadian National Breast Screening Study, and it is likely that over-diagnosis is greater at older than younger ages, as competing causes of death are more common. Other studies that resulted in lower estimates of over-diagnosis were based on indirect observations of the numbers of cancers detected in a population, before and after the introduction of screening programmes, and the extent of over-diagnosis was probably underestimated. ${ }^{23} 24$

\section{Conclusions and policy implications}

The results of the present study may not be generalisable to all countries. Early detection could be of greater benefit in communities where most cancers that present clinically are larger and a higher proportion are node positive. ${ }^{25}$ However, in technically advanced countries, our results support the views of some commentators that the rationale for screening by mammography should be urgently reassessed by policy makers. ${ }^{26}$ Nevertheless, education, early diagnosis, and excellent clinical care should continue to be provided to women to ensure that as many breast tumours as possible are diagnosed at or less than $2 \mathrm{~cm}$.

In conclusion, our data show that annual mammography does not result in a reduction in breast cancer specific mortality for women aged 40-59 beyond that of physical examination alone or usual care in the community. The data suggest that the value of mammography screening should be reassessed.

Contributors: CW collated the data for analysis. PS performed the analysis. SAN, TT, and ABM planned the analysis. ABM and SAN drafted the manuscript. All authors checked the manuscript, tables, and figures for accuracy and completeness. ABM is guarantor.

Funding This study was supported by the Canadian Breast Cancer Research Alliance, Canadian Breast Cancer Research Initiative, Canadian Cancer Society, Health and Welfare Canada, National Cancer Institute of Canada, Alberta Heritage Fund for Cancer Research, Manitoba Health Services Commission, Medical Research Council of Canada, le Ministère de la Santé et des Services Soçiaux du Québec, Nova Scotia Department of Health, and Ontario Ministry of Health. ABM was supported in part by a national health scientist award from Health and Welfare Canada. The study sponsors (funders) had no role in the preparation, approval, or submission of this manuscript.

Competing interests: All authors have completed the ICMJE uniform disclosure form at www.icmje.org/coi_disclosure.pdf and declare: no support from any organisation for the submitted work; no financial relationships with any organisations that might have an interest in the submitted work in the previous three years; no other relationships or activities that could appear to have influenced the submitted work.

Ethical approval: This study was originally approved by the University of Toronto's Human Experimentation Committee. The extended follow-up and its analysis was approved by the Women's College Hospital research ethics board (reference 2007-0025-B)

Data sharing: No additional data available.
Transparency: The lead author (the manuscript's guarantor), ABM, affirms that the manuscript is an honest, accurate, and transparent account of the study being reported; that no important aspects of the study have been omitted; and that any discrepancies are disclosed.

1 Miller AB. Conundrums in screening for cancer. Mini review. Int J Cancer 2010;126:1039-46.

2 Moss S. Over-diagnosis in randomised controlled trials of breast cancer screening. Breast Cancer Res 2005;7:230-4.

3 Welch HG. Over-diagnosis and mammography screening. BMJ 2009;339:182-3.

4 Miller AB, Baines CJ, To T, Wall C. Canadian National Breast Screening Study: 1. Breast cancer detection and death rates among women aged 40 to 49 years. CMAJ 1992;147:1459-76.

5 Miller AB, Baines CJ, To T, Wall C. Canadian National Breast Screening Study: 2. Breast cancer detection and death rates among women aged 50 to 59 years. CMAJ 1992:147:1477-88.

6 Miller AB, To T, Baines CJ, Wall C. Canadian National Breast Screening Study-2: 13-year results of a randomized trial in women age 50-59 years. J Natl Cancer Inst 2000;92:1490-9.

7 Miller AB, To T, Baines CJ, Wall C. The Canadian National Breast Screening Study-1: breast cancer mortality after 11 to 16 years of follow-up. A randomized screening trial of mammography in women age 40 to 49 years. Ann Intern Med 2002;137:305-12.

8 Leger JL, Naimark AP, Beique R, McFarlane DV, Miller S, Miller AB. Report of the "ad hoc" committee on mammography. J Can Assoc Radiol 1974;25:3-21.

9 Report of the Working Group to review the National Cancer Institute-American Cancer Society Breast Cancer Detection Demonstration Projects. J Natl Cancer Inst 1979;62:641-709.

10 Shapiro S, Strax $\mathrm{P}$, Venet $\mathrm{L}$. Periodic breast cancer screening in reducing mortality from breast cancer. JAMA 1971;215:1777-85

11 Shapiro S. Evidence on screening for breast cancer from a randomized trial. Cancer 1977;39:2772-82.

12 Tarone RE. The excess of patients with advanced breast cancer in young women screened with mammography in the Canadian National Breast Screening Study. Cancer 1995;75:997-1003.

13 Mukherjee S. The emperor of all maladies. A biography of cancer. Simon and Shuster, 2010.

14 Canadian Breast Cancer Screening Database (CBCSD). Operational procedures and input data dictionary. Version 6. Public Health Agency of Canada, 2012.

15 Roberts RS, Julian JA, Sweezey D, Muir DC, Shannon HS, Mastromatteo E. A study of mortality in workers engaged in the mining, smelting, and refining of nickel. I: methodology and mortality by major cause groups. Toxicol Ind Health 1989;5:957-74.

16 Baines CJ, Miller AB, Kopans DB, Moskowitz M, Sanders DE, Sickles EA, et al. Canadian National Breast Screening Study: assessment of technical quality by external review. Am $J$ Roentgenol 1990:155:743-7.

17 Miller AB, Baines CJ, Sickles EA. Canadian National Breast Screening Study. Am J Roentgenol 1990;155:1133-4.

18 Baines CJ, McFarlane DV, Wall C. Audit procedures in the National Breast Screening Study: mammography interpretation. Can Assoc Radiol J 1986;37:256-60.

19 Tabár L, Vitak B, Chen TH, Yen AM, Cohen A, Tot T, et al. Swedish two-county trial: impact of mammographic screening on breast cancer mortality during 3 decades. Radiology 2011;260:658-63.

20 Tabar L, Chen H-H T, Duffy SW, Kruesmo UB. Primary and adjuvant therapy, prognostic factors and survival in 1053 breast cancers diagnosed in a trial of mammography screening. Jpn J Clin Oncol 1999;2129:608-16.

21 Narod SA. On being the right size: a reappraisal of mammography trials in Canada and Sweden. Lancet 1997;349:1846.

22 Bleyer A, Welch HG. Effect of three decades of screening mammography on breast-cancer incidence. N Engl J Med 2012;367:1998-2005.

23 Zackrisson S, Andersson I, Janzon L, Manjer J, Garne JP. Rate of over-diagnosis of breast cancer 15 years after end of Malmö mammographic screening trial: follow-up study. BMJ 2006;332:689-92.

24 Zahl PH, Gøtzsche PC, Mæhlen J. Natural history of breast cancers detected in the Swedish mammography screening programme: a cohort study. Lancet Oncol 2011;12:1118-24.

25 Narod SA. Tumour size predicts long-term survival among women with lymph node-positive breast cancer. Curr Oncol 2012;19:249-53.

26 Gøtzsche PC, Jørgensen KJ, Zahl P-H, Mæhlen J. Why mammography screening has not lived up to expectations from the randomised trials. Cancer Causes Control 2012;23:15-21.

Accepted: 16 January 2014

\section{Cite this as: BMJ 2014;348:g366}

This is an Open Access article distributed in accordance with the Creative Commons Attribution Non Commercial (CC BY-NC 3.0) license, which permits others to distribute, remix, adapt, build upon this work non-commercially, and license their derivative works on different terms, provided the original work is properly cited and the use is non-commercial. See: http://creativecommons.org/licenses/by-nc/3.0/. 


\section{What is already known on this topic}

Women with non-palpable breast cancer detected by mammography experience long term survival that is superior to that of women with palpable breast cancer

It is not known with accuracy to what extent the survival difference is a consequence of organised screening or of lead time bias and over-diagnosis

\section{What this study adds}

Annual mammography screening detected a significant number of small non-palpable breast cancers, but half of these were examples of over-diagnosis

$22 \%$ of the screen detected invasive cancers in the mammography arm were over-diagnosed, representing one over-diagnosed breast cancer for every 424 women who received mammography screening in the trial

Annual mammography screening had no effect on breast cancer mortality beyond that of breast physical examinations

\section{Tables}

\section{Table 1 | Number of breast cancers diagnosed in mammography arm and control arm, by study year}

\begin{tabular}{|c|c|c|c|c|}
\hline \multirow[b]{2}{*}{ Year of study } & \multicolumn{2}{|c|}{ Mammography arm ( $n=44$ 925) } & \multicolumn{2}{|c|}{ Control arm $(n=44910)$} \\
\hline & No of cancers detected & Mean size $(\mathrm{cm})$ & No of cancers detected & Mean size $(\mathrm{cm})$ \\
\hline 1 & 253 & 1.87 & 170 & 2.03 \\
\hline 2 & 109 & 2.05 & 89 & 2.19 \\
\hline 3 & 101 & 1.64 & 89 & 2.11 \\
\hline 4 & 111 & 2.01 & 86 & 2.08 \\
\hline 5 & 92 & 1.98 & 90 & 2.13 \\
\hline Subtotal years 1-5 & 666 & 1.91 & 524 & 2.10 \\
\hline 6 & 83 & 2.15 & 83 & 2.42 \\
\hline 7 & 82 & 1.99 & 93 & 2.24 \\
\hline 3 & 107 & 2.01 & 133 & 2.04 \\
\hline 9 & 115 & 1.86 & 119 & 1.90 \\
\hline 10 & 127 & 1.69 & 128 & 1.71 \\
\hline Subtotal years 6-10 & 514 & 1.93 & 556 & 2.05 \\
\hline Subtotal years 11-25 & 2070 & - & 2053 & - \\
\hline Subtotal years 6-25 & 2584 & - & 2609 & - \\
\hline Total years 1-25 & 3250 & - & 3133 & - \\
\hline
\end{tabular}


Table 2/ Comparison of breast cancers detected during screening phase (years 1 to 5 ) in mammography arm versus control arm. Values are numbers (percentages) unless stated otherwise

Cancers in mammography arm

Variables

Control arm $(n=524)$ Detected $(n=666)$ Palpable $(n=454)$ Non-palpable $(n=212)$

Mean (range) age at diagnosis (years) $52.6(40-64)$ $52.5(40-64)$ $52.1(40-64)$ $53.3(46-64)$

Died from breast cancer:

\begin{tabular}{lcccc}
\hline No & $353(67.4)$ & $486(73.0)$ & $316(69.6)$ & $170(80.2)$ \\
\hline Yes & $171(32.6)$ & $180(27.0)$ & $138(30.4)$ & $42(19.8)$ \\
\hline Mean (range) age at death (years) & $60.6(43-83)$ & $59.9(43-80)$ & $59.1(43-80)$ & $62.5(46-77)$ \\
\hline Tumour size (cm) & $2.1(0.2-7.0)$ & $1.9(0.2-9.0)$ & $2.1(0.2-9.0)$ & $1.4(0.2-9.0)$ \\
\hline Missing data & $58(11.1)$ & $87(13.1)$ & $56(12.3)$ & $31(14.6)$ \\
\hline Lymph node status: & & & & $142(67.0)$ \\
\hline Negative & $303(57.8)$ & $394(59.2)$ & $252(55.5)$ & $35(16.5)$ \\
\hline Positive & $170(32.4)$ & $204(30.6)$ & $169(37.2)$ & $35(16.5)$ \\
\hline Missing data & $51(9.7)$ & $68(10.2)$ & $33(7.3)$ & $30(14.2)$ \\
\hline Oestrogen receptor status: & & & $74(21.4)$ & $8(3.8)$ \\
\hline Negative & $85(16.2)$ & $102(15.3)$ & $33(9.5)$ & $78(36.8)$ \\
\hline Equivocal & $41(7.8)$ & $41(6.2)$ & $239(69.1)$ & $96(45.3)$ \\
\hline Positive & $261(49.8)$ & $312(46.9)$ & $138(30.3)$ & \\
\hline Missing data & $137(26.2)$ & $211(31.7)$ & & \\
\hline
\end{tabular}


Table 3| Deaths from breast cancer to 31 December 2005, by study arm and year of diagnosis. Values are numbers (percentages) unless stated otherwise

\section{Deaths by study arm}

Study year

Mammography $(n=44925)$

Control $(n=44910)$

Deaths from breast cancers detected in years 1-5 (screening period)*

\begin{tabular}{lcc}
\hline Screen detected, year 1 & $52(28.9)$ & $26(15.2)$ \\
\hline Screen detected, years 2-5 & $63(35.0)$ & $29(17.0)$ \\
\hline Interval cancers, years 1-5 & $46(25.6)$ & $44(25.7)$ \\
\hline Incident cancers, year 5 & $19(10.6)$ & $72(42.1)$ \\
\hline Screen period, total & $180(100)$ & $171(100)$ \\
\hline Breast cancer deaths per 10 000 women from cancers detected in years 1-5 & 40.1 & 38.1 \\
\hline Deaths from breast cancers detected in years 6-25 (follow-up period)* & 298 & 321 \\
\hline Breast cancer deaths per 10 000 women from cancers detected in years 6-25 & 66.3 & 71.4 \\
\hline Total deaths(all breast cancers, all years) & 500 & 108.4 \\
\hline Breast cancer deaths per 10 000 women (all breast cancers, all years) & 110.2 \\
\hline
\end{tabular}

*Year of diagnosis was not available for 35 additional women, 22 in mammography arm and 13 in control arm. 


\section{Figures}

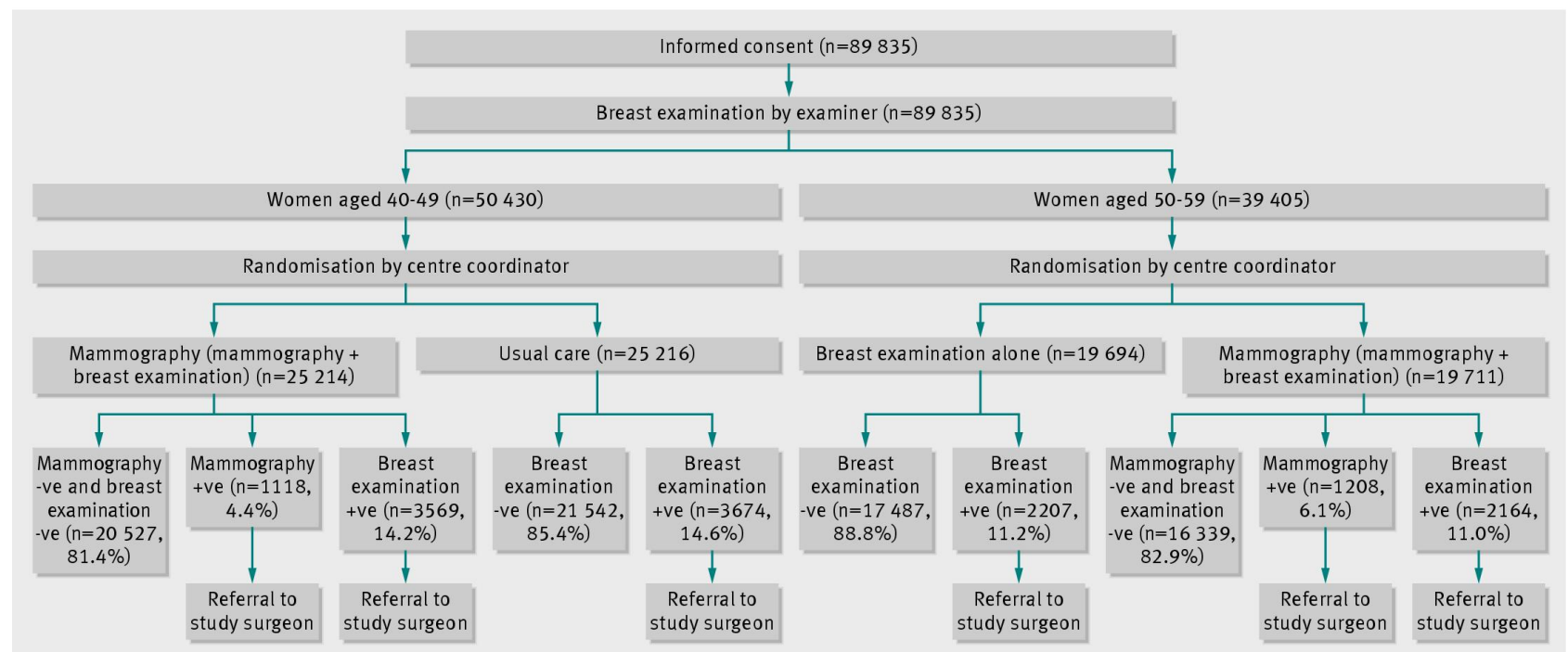

Fig 1 Process of randomisation and initial screening (screen 1). Breast examination was carried out by nurses unless stated otherwise (+ve indicates abnormality found by examiner, -ve no abnormality found). MA=mammography (+ve indicates abnormality found by radiologist, -ve no abnormality found). Study surgeon could order diagnostic mammography or consult with the study radiologist if necessary before sending recommendations to family doctors. Bracketed interventions indicate protocol at subsequent screens

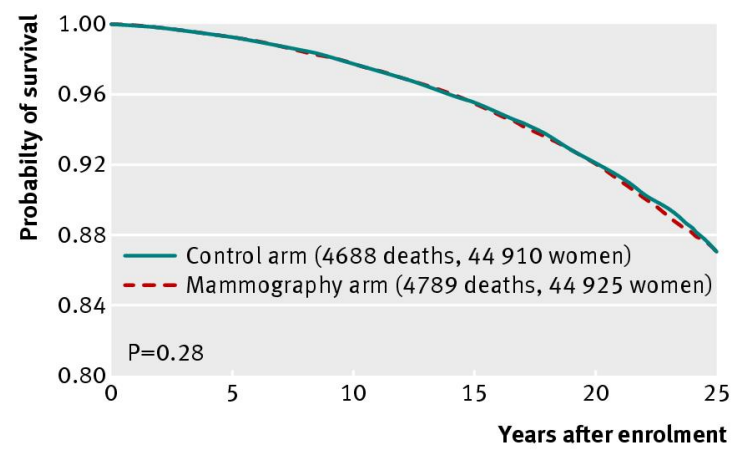

Fig 2 All cause mortality, by assignment to mammography or control arms (all participants)

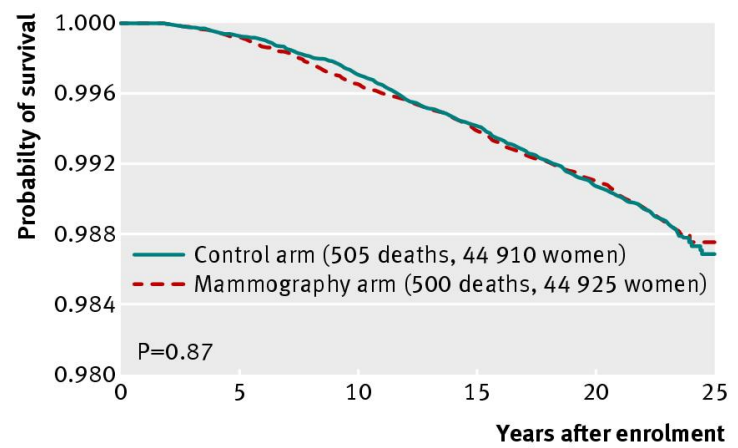

Fig 3 Breast cancer specific mortality, by assignment to mammography or control arms (all participants) 


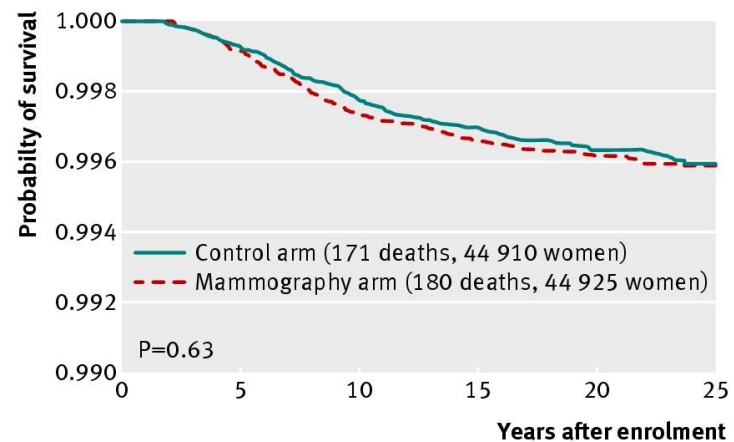

Fig 4 Breast cancer specific mortality from cancers diagnosed in screening period, by assignment to mammography or control arms 